lems. Subtotal tumour resection with radiotherapy is an alternative treatment.

The differential diagnosis of growth failure is broad, and making a diagnosis can be challenging, especially when the presenting symptoms are nonspecific (Box I). This case illustrates the importance of considering central nervous system pathology in children with growth failure, especially when it is accompanied by symptoms of headache and vomiting.

\section{Chantelle Barnard}

Division of Hospital Pediatrics

Department of Pediatrics

Alberta Children's Hospital

Calgary, Alta.

Jeremy N. Friedman

Division of Pediatric Medicine

Department of Pediatrics

Faculty of Medicine

University of Toronto

Hospital for Sick Children

Toronto, Ont.
Competing interests: None declared.

\section{REFERENCES}

I. Behrman R. Nelson textbook of pediatrics. $\mathrm{I}^{\text {th }} \mathrm{ed}$. London: Saunders; 2003. p. 133-4, I702-7, I854.

2. Thomsett MJ, Conte FA, Kaplan SL, et al. Endocrine and neurologic outcomes in childhood craniopharyngioma: review of effect of treatment in 42 patients. J Pediatr 1980;97:728-35.

3. Sklar CA. Craniopharyngioma: Endocrine abnormalities at presentation. Pediatr Neurosurg I994; 2I(suppl I):I8-20.

\section{Public Health}

\section{Taking away the sting}

\section{of malaria}

M ore than $40 \%$ of the world's population is at risk of malaria, and more than a million people die of it each year. Malaria kills a child every 30 seconds: $90 \%$ of people who die from malaria are children not yet 5 years of age, and most (90\%) of these deaths take place in sub-Saharan Africa. ${ }^{1}$

Where malaria is endemic, related illness and death have severe economic as well as human costs. It is estimated that US\$12 billion is lost in Africa each year to the costs of care and reduced productivity, and that a high endemic malaria burden lowers the growth of a country's annual GNP (gross national product) by $2 \% .{ }^{1}$

Currently, affected countries are beset by limited access to rapid diagnostic tests and to the resources required to support prevention strategies and overcome drug resistance. Turning the malaria problem around requires an

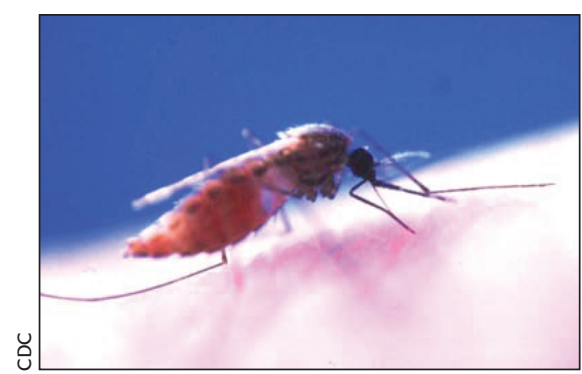

ongoing multipronged attack emphasizing both prevention and treatment.

Malaria is commonly diagnosed and treated according to clinical symptoms rather than laboratory test results; the result of this is that many of the people treated may not in fact be infected. Appropriate diagnosis is limited by a lack of laboratory services, or services of poor quality; and although rapid tests (which are currently effective for Plasmodium falciparum infections only) are available, they are not widely accessible because of their cost. ${ }^{1}$ The lack of good diagnostic tests increases drug use (and costs), and contributes to more rapid development of drug resistance. ${ }^{2}$

The treatment of malaria has also become increasingly problematic. Common and sequential use of monotherapies and reliance on quinoline and antifolate compounds have contributed to a burgeoning problem of drug resistance. ${ }^{1,2}$ In an effort to combat ineffective treatment, the World Health Organization (WHO) has recommended that all countries where resistance to conventional monotherapies such as chloroquine or amodiaquine is common or growing use combination therapies (CTs), preferably ones containing artemisinin derivatives (ACTs). As an indication to switch to ACTs, WHO has also lowered the endemic resistance threshold from $25 \%$ to $15 \%$ among children younger than 5 years. ${ }^{2}$

WHO's change in recommendation follows evidence that ACTs are well tolerated, produce rapid therapeutic responses, are effective against $P$. falcipar-
Box 1: Who is working on malariarelated issues?

- Roll Back Malaria (RBM): www.rbm.who.int

- Global Fund to Fight AIDS, Tuberculosis and Malaria (GFATM): www.theglobalfund.org

- Bill and Melinda Gates Foundation: www.gatesfoundation.org

- PATH Malaria Vaccine Initiative (MVI): www.malariavaccine.org

- Medicines for Malaria Venture (MMV): www.mmv.org

- Multilateral Initiative on Malaria (MIM): www.mim.nih.org

- Drugs for Neglected Diseases Initiative (DNDi)

- Malaria R\&D Alliance: www.malariaalliance.org

um and can cure infections after just 3 days of treatment. ${ }^{2}$ They also reduce gametocyte carriage and may therefore reduce malaria transmission. To improve ease of use, a fixed-dose combination ( 2 drugs combined in one pill) and dissolvable pills for children are being developed.

Despite clear indications for their use, in 2005 ACTs were used in the public sectors of only 9 countries in Africa. This is partly due to increased cost: ACTs cost Io times that of older therapies. ${ }^{1}$ Although the Global Fund for Fighting AIDS, Tuberculosis and Malaria, the largest funder of ACTs in developing countries, has committed US\$4I million for ACT purchases, the 
cost of estimated global requirements (I32 million courses, in 2005) far exceeds the funding available. ${ }^{2}$ The decision to encourage many African countries at once to change to ACTs has also led to global shortages of the drugs, a problem exacerbated by the 6 months

\section{Box 2: A recent encouraging} development

The Bill and Melinda Gates Foundation committed US\$258 million to vaccine, drug and mosquito-control research and development in Oct. 2005. The Malaria R\&D Alliance, an international coalition of malaria research groups, reported that global funding in 2004 for malaria research was just $\$ 323$ million - less than $0.3 \%$ of total health-research spending worldwide. The donation from the Gates Foundation will boost research and development considerably. of cultivation needed for Artemisia annua plants plus the time required for processing and manufacturing. ${ }^{1}$

In the meantime, prevention efforts are continuing. Bed nets are being widely promoted, although mass distribution is difficult. In Africa, 30 million nets per year are currently required to meet the target of having $60 \%$ of at-risk populations, including young children and pregnant women, protected by nets within 3 years. ${ }^{3}$ Insecticidal bed nets are being developed that last for 4-5 years without requiring retreatment with insecticide, which would improve prevention efforts.

Intermittent treatment regimens are also recommended for pregnant women to prevent malarial episodes. Pregnant women are particularly vulnerable because of their lowered immunity. Intermittent treatment, involving at least 2 preventive treatments with an effective antimalarial drug during antenatal

\section{Box 3: Malaria prevention and treatment goals}

UN Millennium Development Goals: Target 6

- Halt (by 2015) and begin to reverse the incidence of malaria and other major diseases

Abuja Malaria Summit 2000 targets

By the end of 2005 , at least $60 \%$ of:

- people with malaria must have access to treatment within 24 hours of onset of symptoms

- those at risk of malaria should benefit from a combination of personal and community preventive measures, such as insecticide-treated bed nets

- pregnant women at risk of malaria will have access to preventive treatment

- epidemics will be detected within 2 weeks of onset

- epidemics will be responded to within 2 weeks of detection

clinic visits, has been shown to reduce the number of infants with low birth weights. ${ }^{3}$

Finally, clinical trials of malaria vaccines are underway, and new insecticides that are safe for the environment and for people are being developed for larval control.

Current challenges facing malaria control are not new. The battle to control malaria at a global level began with WHO's vector-control programs in the I950s; as mortality rates rose, WHO introduced the Roll Back Malaria (RBM) program in 1998 . Now, other international partners (Box I) are supporting the development of effective diagnostics, treatment (Box 2) and global management of malaria. It is now up to WHO and its partners to make sure the prevention and treatment objectives outlined in the UN Millennium Development Goals and the 2000 African leaders' summit (Box 3) are met: appropriate and quick treatment, accessible prevention measures and effective epidemic control.

\section{Sally Murray \\ Editorial Fellow \\ CMAJ}

\section{REFERENCES}

I. Greenwood BM, Bojang K, Whitty C, et al. Malaria. Lancet 2005; 365:1487-8.

2. World Health Organization. Roll back malaria: facts on artemisinin-based combination therapies. Geneva: WHO; 2005. Available: www.rbm.who.int /cmc_upload/o/ooo/or5/364/RBMInfosheet_9.htm (accessed 2005 Dec 8).

3. Global Fund for Fighting AIDS, Tuberculosis and Malaria (GFATM). HIV/AIDS, tuberculosis and malaria: the status and impact of the three diseases. Geneva: GFATM; 2005.

\section{LEADERSHIP}

$C M A J$ is a founding member of the International Committee of Medical Journal Editors, an organization that is devoted to ensuring the highest integrity in scientific publishing and is a driving force in the mandatory registration of clinical trials. 